\title{
Evaporation and heat transfer from thin water films on vertical panels in simulated fire conditions
}

\author{
J. de Vries, K. V. Meredith \& Y. Xin \\ Research Division, FM Global, Norwood, USA
}

\begin{abstract}
Understanding and quantifying the interaction of water films and external radiation on vertical walls is critical for fire suppression model validation. In this study, evaporation rates and surface temperatures on heated stainless steel (SS) and corrugated paperboard (CP) vertical panels were measured. External radiant heat flux was provided by an intermediate scale calorimeter (ICAL). Heat flux levels ranged between 7 and $46 \mathrm{~kW} / \mathrm{m}^{2}$ and were controlled by varying the distance between the ICAL and the target panel. Water flows ranging between 70 and $1900 \mathrm{ml} / \mathrm{min}$ were used in this study. Surface temperatures were measured by a custom calibrated long-wave infrared (IR) camera. Thermocapillary instabilities caused water films to quickly break down into individual rivulets when exposed to external radiation. The maximum surface temperatures on the SS panels were lower than those measured on CP panels due to more effective lateral conduction. The results also showed that water flows on SS surfaces are more effective in extracting heat than similar water flows on CP panels. The experimental results are expected to help understand multi-phase heat transfer for surface flows in fire environments, and to provide validation data for developing numerical models.

Keywords: IR imaging, film flow, rivulets, evaporation, FireFOAM, fire suppression, thermal radiation, ICAL.
\end{abstract}

\section{Introduction}

Understanding burning surface and water film interaction is crucial when describing water-based fire protection, particularly for sprinkler applications; however, there exists little knowledge and experimental data on this important 
phenomenon [1]. Meredith et al. [2] developed a novel framework for sprinklerbased fire suppression modeling. This framework includes detailed interaction of water sprays and films with solid surfaces. This computational fluid dynamic model (CFD), FireFOAM, was developed in the OpenFOAM [3] framework and incorporates physics-based models for turbulent combustion [4], soot [5], radiation [6], and pyrolysis [7]. Meredith et al. [2] showed thin water films, when exposed to external radiation, first bead up into individual rivulets due to the Marangoni effect, which allows dry regions trapped between rivulets to create pyrolysis gases; adding to the overall heat release rate and to more water evaporation. The Marangoni effect described mass transfer along the water film's surface due to a thermally induced gradient in surface tension. The waterfilm portion of FireFOAM was previously validated for continuous film flows at multiple inclination angles [8]; modeled results matched the Nusselt solution for film flows at Reynolds numbers common in fire suppression situations. In addition, the model's surface tension and finite contact angle in components were validated using wetted area fraction measurements [9]. More detailed heat transfer effects and evaporation on inert surfaces was validated using stainless steel surfaces [2].

Dry burning corrugated vertical surfaces have been studied extensively, for instance, Khan et al. [10] studied upward fire growth over thermally thin corrugated paperboard and Chaos et al. [11] studied single and triple wall corrugated materials in parallel panel configurations. Experiments on burning, wetted surfaces, however, are comparatively rare.

In this study, evaporation rates and surface temperatures were measured on vertical corrugated paperboard panels with a constant water flux entering from the top. Evaporation results were measured and compared against evaporation rates measured on inert (stainless steel) surfaces. The experimental results obtained in this study are expected to improve our physical understanding of multiphase flows in fire suppression situations, and provide validation data for predictive numerical model development, such as FireFOAM.

\section{Experimental setup}

The present work focuses on flame radiation and water flow interactions on vertical surfaces in a simulated fire environment. Since real fire conditions are dominated by flame radiation, steady-state external radiation was employed to simulate flame heat transfer from the fires. In this study, external radiation was provided via an intermediate scale calorimeter (ICAL), similar to the one developed by Urbas and Luebbers [12]. The ICAL can be used for standardized testing and is described in detail in ASTM E-1623 [13] and ISO/TR 14696 [14]. The ICAL is capable of producing uniform radiant heat fluxes up to $50 \mathrm{~kW} / \mathrm{m}^{2}$ on a $1 \mathrm{~m}$ by $1 \mathrm{~m}$ target via twenty-four individually controlled burners.

Water films ranging between 70 and $1900 \mathrm{ml} / \mathrm{min}$ were fed to the panel's top via a small basin. For both the stainless steel and the corrugated panels, smooth, laminar and uniform water films were created via a small piece of cloth draped over the top of the vertical panel. Evaporation rates were determined by taking 
the difference between water flow rates at the plate's top and bottom. Flow rates at the bottom were measured using a stainless steel collection pan centered on a load cell (GSE series $4440,0-181 \mathrm{~kg}$ ) accurate to \pm 5 g. Flow rates on the plate's top were determined by flowing water for two minutes onto the load cell in the absence of external radiation.

The corrugated material used in this study consisted of a single layer of $15.2 \mathrm{~mm}$ thick, $106 \mathrm{~cm}$ high, and $61 \mathrm{~cm}$ wide double-wall corrugated paperboard $\left(1.9 \mathrm{~kg} / \mathrm{m}^{2}\right)$. Detailed description and characterization of the corrugated material used in this study is presented by Chaos et al. [15]. The experimental setup for the corrugated case is shown in Fig. 1.

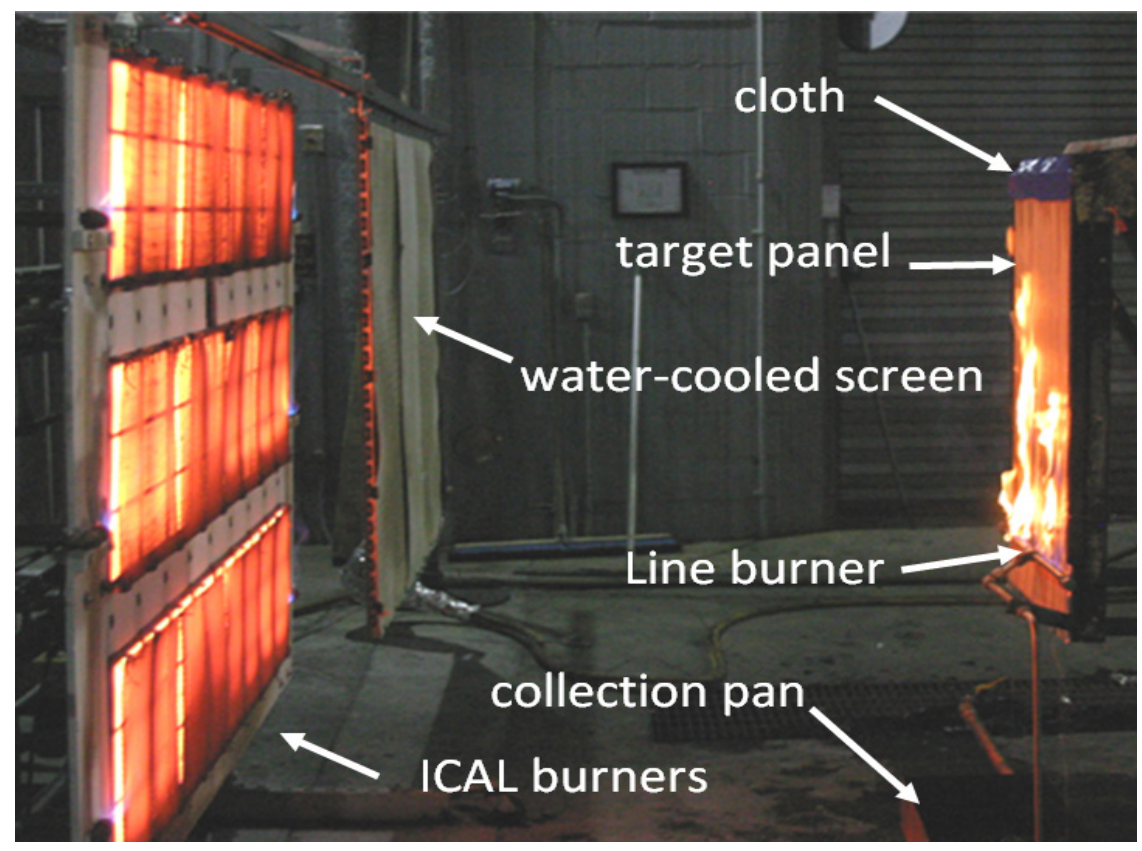

Figure 1: $\quad$ Experimental setup with the ICAL (left) and CP panel (right).

For all corrugated samples, ignition along the panel's bottom was established via a propane-fed (2 lpm) line burner; creating a heat release rate of $3.3 \mathrm{~kW} / \mathrm{m}$ along the lateral width $(61 \mathrm{~cm})$. The effect of igniter strength on vertical flame spread to be insignificant at this level [16].

The stainless steel panel consisted of a $0.19 \mathrm{~mm}$ thick, $91 \mathrm{~cm}$ high, and $61 \mathrm{~cm}$ wide plate coated with high emissivity paint on both sides. The stainless steel panel setup is described in more detail elsewhere [1]. The igniter was removed for all tests with the stainless steel panel.

The spectral distribution from the ICAL's surface was measured and compared with a burning corrugated paperboard panel. Figure 2 shows the radiation intensity versus wavelength of the ceramic surface of the ICAL measured using a mid-wave spectrometer (Spectraline ES200, 1-5 $\mu \mathrm{m}$ ). The 
spectral distribution follows mostly that of a gray body, where the emissivity, $\varepsilon$, is invariant with respect to wavelength, $\lambda$, Figure 3 shows intensity versus wavelength of a burning corrugated surface.

Both intensities the ICAL and the corrugated paperboard follow Planck's distribution describing a gray body with the exception of the localized absorption by the water vapor $(2.8 \mu \mathrm{m})$ and $\mathrm{CO}_{2}(4.2 \mu \mathrm{m})$. The spectral analysis showed

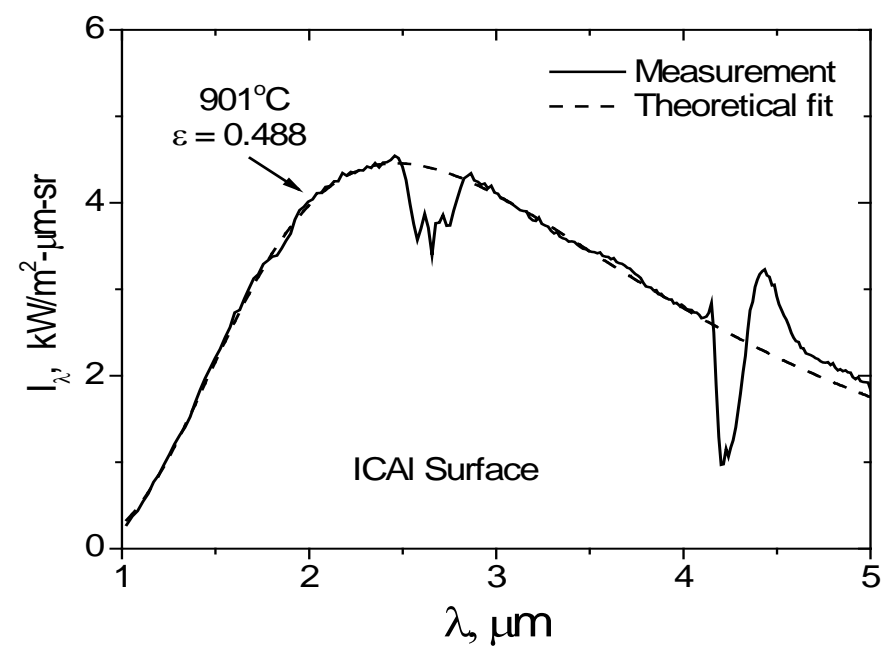

Figure 2: Intensity versus wavelength measured from the ICAL's surface.

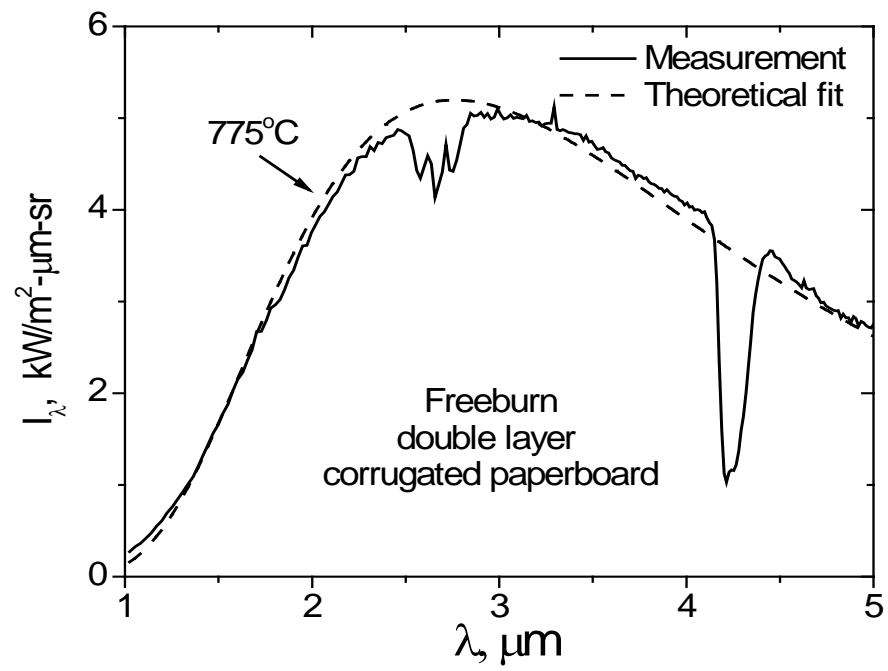

Figure 3: Intensity versus wavelength measured from a burning vertical CP panel. 
that the ICAL forms a realistic spectral representation of the radiation created by burning cellulose material. The total radiation intensity from the ICAL onto the target panel was controlled by changing the separation distance. Prior to all tests; separate calibration tests were performed to determine the relationship between distance and measured external radiation intensity. The radiant intensity was measured using three Schmidt-Boelter type heat flux gauges $\left(0-100 \mathrm{~kW} / \mathrm{m}^{2}\right)$ placed on the target panel's vertical center line, spaced $30 \mathrm{~cm}$ apart. Figure 4 shows the calibration results with distances ranging between $30 \mathrm{~cm}$ and $229 \mathrm{~cm}$ with corresponding heat fluxes ranging between $51 \mathrm{~kW} / \mathrm{m}^{2}$ and $7 \mathrm{~kW} / \mathrm{m}^{2}$, respectively.

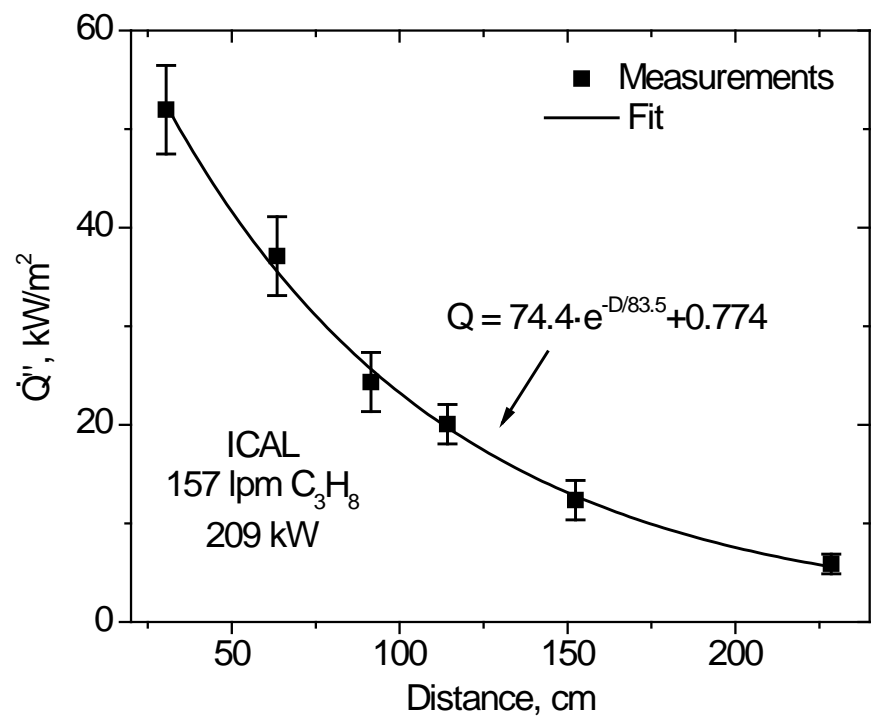

Figure 4: $\quad$ Measured heat flux $\left(\mathrm{kW} / \mathrm{m}^{2}\right)$ versus distance $(\mathrm{cm})$.

The average heat flux $\left(\mathrm{kW} / \mathrm{m}^{2}\right)$ from the three Schmidt-Boelter gauges was best correlated by using the following exponential decay function.

$$
Q_{\text {rad }}^{\prime \prime}=74.4 \cdot e^{-\frac{D}{83.5}}+0.774
$$

where $D$ is the distance between the ICAL and the target panel in centimeters. Heat flux uniformity on the target panel was within $10 \%$ (at $30 \mathrm{~cm}$ ) with even better uniformity seen at greater separation distances.

Infrared thermography was performed using a long-wave $(7.5 \mu \mathrm{m}-13 \mu \mathrm{m})$ camera (FLIR ${ }^{\circledR}$, SC655). The high intensities of incoming radiation from burning surfaces (falling outside the factory calibrated range of this camera) were reduced via a $1.27-\mathrm{cm}$ diameter reduced aperture. Details on extending the SC655 usable range using this technique are described elsewhere [1]. Thermal imaging allowed the characterization of water-film breakup due to Marangoni effects and the subsequent rivulet formation. 


\section{Results}

Some infrared images taken during the steady state period for both stainless steel (SS) and corrugated paperboard (CP) surfaces are shown in Figs. 5 and 6. Figure 5 shows stainless steel surfaces (left) and corrugated surfaces (right) exposed to $12 \pm 1 \mathrm{~kW} / \mathrm{m}^{2}$. In Figs. 5(a) and (b), $1893 \mathrm{ml} / \mathrm{min}$ of water is supplied on top. In Figs. 5(c) and (d), $195 \pm 5 \mathrm{ml} / \mathrm{min}$ of water (approximately $1 / 10^{\text {th }}$ ) is supplied on top of the surface.

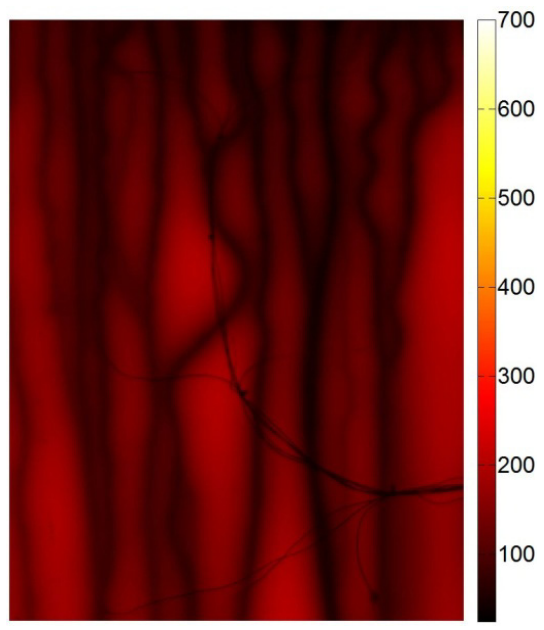

(a) $\dot{m}_{w, i n}=1893 \mathrm{ml} / \mathrm{min}$

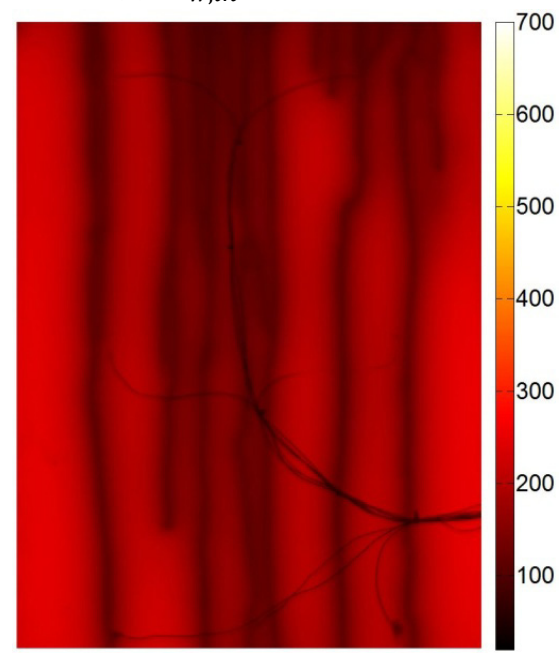

(c) $\dot{m}_{w, \text { in }}=190 \mathrm{ml} / \mathrm{min}$

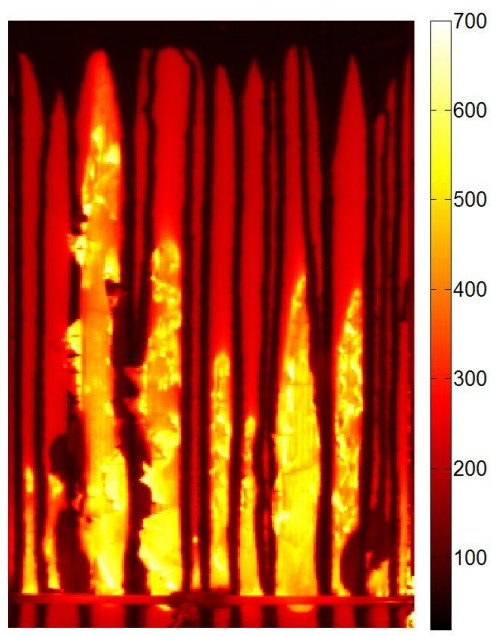

(b) $\dot{m}_{w, i n}=1893 \mathrm{ml} / \mathrm{min}$

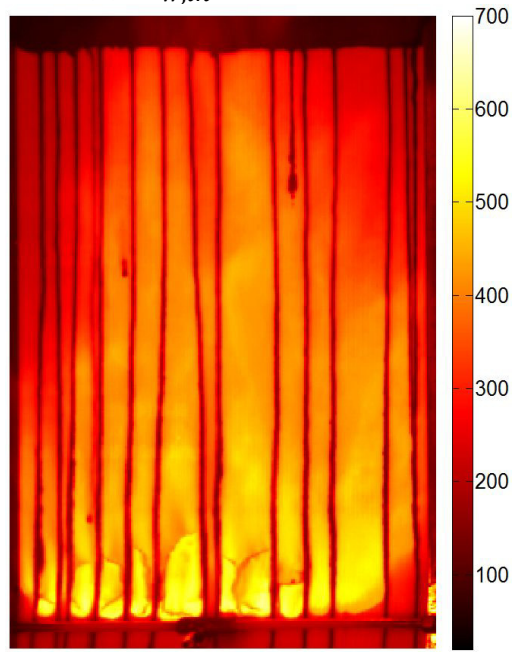

(d) $\dot{m}_{w, i n}=201 \mathrm{ml} / \mathrm{min}$

Figure 5: $\quad$ Long-wave IR images of SS (left) and CP (right) surfaces exposed to $12 \pm 1 \mathrm{~kW} / \mathrm{m}^{2}$. 
Figure 6 shows stainless steel surfaces (left) and corrugated surfaces (right) exposed to $23 \mathrm{~kW} / \mathrm{m}^{2}$. In Figs. 6(a) and (b), 946-1136 $\mathrm{ml} / \mathrm{min}$ of water is supplied on top. In Figs. 6(c) and (d), 190-198 ml/min of water (approximately $1 / 5^{\text {th }}$ ) is supplied on top of the surface.

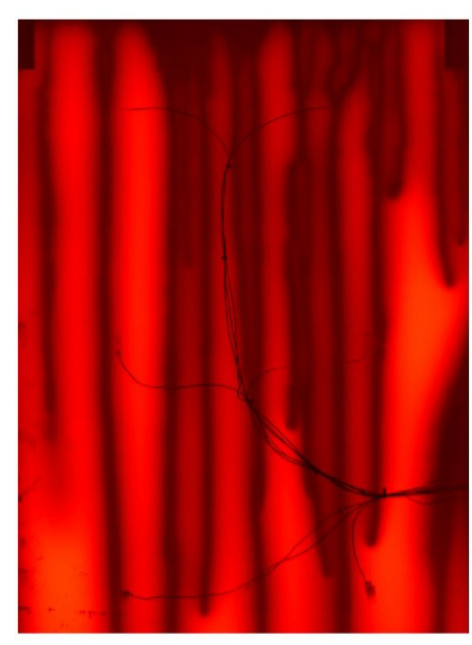

(a) $m \cdot{ }_{w, i n} \mathrm{H} 36 \mathrm{ml} / \mathrm{min}$

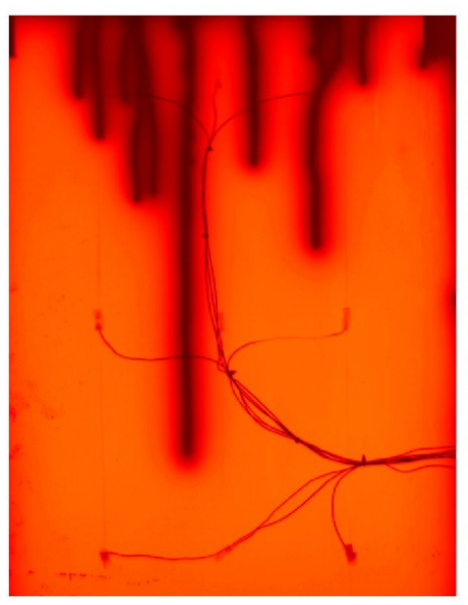

(c) $\dot{m}_{w, i n}=190 \mathrm{ml} / \mathrm{min}$

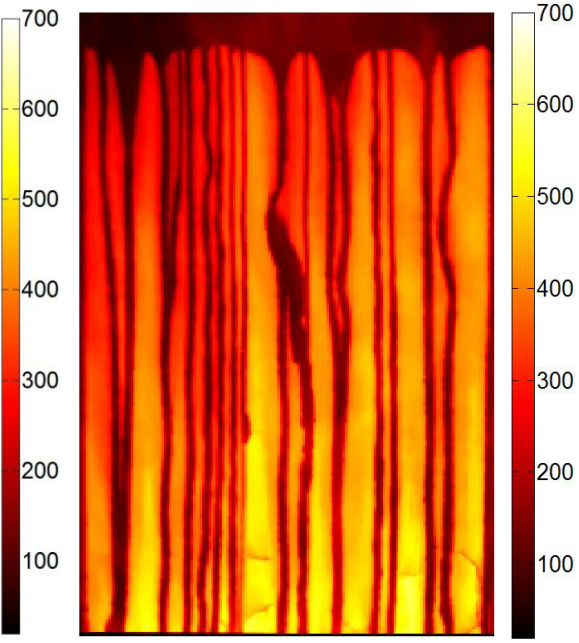

(b) $m \cdot{ }_{w, i n} \mathrm{H} 36 \mathrm{ml} / \mathrm{min}$

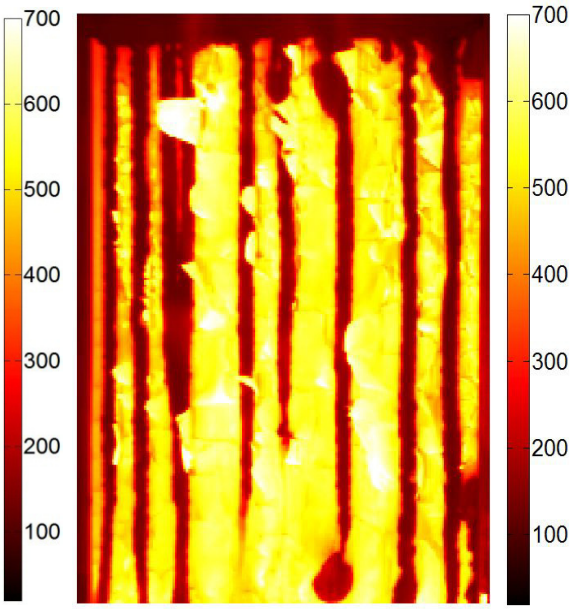

(d) $\dot{m}_{w, \text { in }}=189 \mathrm{ml} / \mathrm{min}$

Figure 6: $\quad$ Long-wave IR images of SS (left) and CP (right) surfaces exposed to $23 \mathrm{~kW} / \mathrm{m}^{2}$.

Figure 7 shows the evaporated fraction as a function of normalized heat flux on both the SS (black solid squares) and CP (blue open squares) surfaces. When 
all water evaporates the evaporated fraction reaches unity. The normalized heat flux, $Q^{*}$, is defined as

$$
Q^{*}=\frac{A_{s} \dot{Q}_{r a d}^{\prime \prime}}{\dot{m}_{w, i n} \Delta H_{v a p}}
$$

where $A_{s}\left(\mathrm{~m}^{2}\right)$ is the targets surface area, $\dot{Q}_{\text {rad }}^{\prime \prime}\left(\mathrm{kW} / \mathrm{m}^{2}\right)$, is the radiant heat flux from the ICAL, $\dot{m}_{w, i n}(\mathrm{~g} / \mathrm{s})$, is the water mass flux into the system, and $\Delta H_{v a p}$ $(\mathrm{kJ} / \mathrm{g})$ is the amount of energy required to vaporize one gram of water with an initial temperature of $20^{\circ} \mathrm{C}$. The denominator in Eqn. (2) represents the "cooling power” by the supplied water flux.

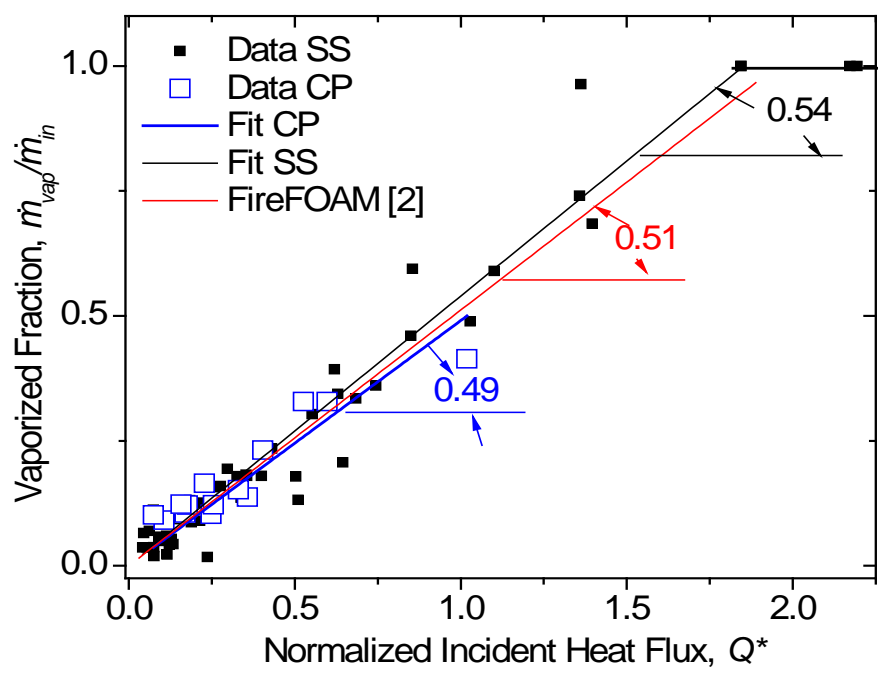

Figure 7: Vaporized fraction versus normalized heat flux for SS and CP vertical panels.

Also included in Fig. 7 is the evaporation results from the numerical model; FireFOAM (red). This thin film model has been described in more detail previously [2, 8-9]. In short the thin film model includes three transport equations; conserving continuity, momentum, and energy. The thin film is solved on a one cell "deep" mesh. The film thickness is one of the model's scalar output properties. The thin film model includes surface tension and thermocapillary instabilities in addition to finite contact angle forces. These surface tension forces combined with vaporization lead to rivulet flow and partially wetted conditions. In this study, the model's heat transfer input parameters were determined and validated through separate temperature measurements on dry panels exposed to external radiation. More details on these modeled results are reported elsewhere [2]. 


\section{Discussion}

The initial condition before each test was a fully flooded film. The infrared images clearly show the breakup of continuous water films into individual rivulets when exposed to external radiation. The maximum temperatures on the $\mathrm{CP}$ surfaces are approximately twice the temperatures measured on the SS surfaces when tested at similar conditions. The CP surfaces can be seen "flaking" off the surface. These charred surfaces are heated by the surrounding fire and can reach high $\left(700^{\circ} \mathrm{C}+\right)$ incandescent temperatures. None of the rivulets make it down to the bottom of the panel when the evaporated fraction reaches unity, as can be seen in Fig. 6(c).

One interesting observation is that the number of rivulets in Fig 5(b) and (d) are similar; however, the average rivulet's thickness in Fig. 5(b) is much greater due to the higher water flux. The data shown in Fig. 7 is fitted linearly and each fit's slope represents the efficiency by which heat is extracted from the surface.

For the SS panel, the slope is 0.54, for the CP panel, the slope was found to be 0.49 . The FireFOAM results (red) agree well with the measured values on stainless steel material, i.e., 0.51. Performing tests at high values of $Q^{*}$ on CP panels was difficult due to severe flaking, peeling or other surface disturbances on the burning corrugated surfaces; however, the evaporation rates were measured to be only slightly lower on the CP panels versus the SS panels and the results mostly fall within the observed scatter.

In theory, the evaporation rates on the corrugated surfaces were expected to be lower due to the reduced hear transfer in the lateral direction; however, this effect could be offset by the fact that there is limited heat transfer through the corrugated panel's back. Also, the heat flux observed by the corrugated paperboard panels is enhanced due to the flames' presence and, to a lesser extent, the line burner.

\section{Conclusions}

Understanding the interaction between radiant heat flux and water films is important when developing fire suppression models. In this study, several evaporation and temperature measurements were performed on stainless steel (SS) and corrugated paperboard (CP) surfaces exposed to radiant heat fluxes up to $46 \mathrm{~kW} / \mathrm{m}^{2}$. Experimental results showed the maximum temperatures measured on the stainless steel panels were lower due to improved heat transfer in the tangential direction. Evaporated fractions show to linearly depend on nondimensionalized radiant heat flux until the evaporated fraction reached unity (all water evaporated). The experimental results are expected to help understand multi-phase heat transfer for surface flows in fire environments, and to provide validation data for developing numerical models.

\section{Acknowledgements}

This work was funded by FM Global under the Strategic Research Programs for Fire Modeling and Sprinkler Technology. The authors would like to thank 
Mr Jeff Chaffee, Mr Jason Tucker and Mr Mark Bardol for their help with performing the experiments.

\section{References}

[1] de Vries, J., Xin Y., and Meredith, K.V., An experimental study of fire suppression physics for sprinkler protection, Fire Safety Science, 10 pp. 429-442, 2011.

[2] Meredith K.V., de Vries, J., Wang, Y., and Xin, Y., A comprehensive model for simulating the interaction of water with solid surfaces in fire suppression environments, Proceedings of the Combustion Institute, 34(2), pp. 2719-2726, 2013.

[3] Weller, H.G., Tabor, G., Jasak, H., and Fureby, C., A tensorial approach to computational continuum mechanics using object-oriented techniques, Computers in Physics 12(6) pp. 620-631, 1998.

[4] Wang, Y., Chatterjee, P., and de Ris, J.L., Large eddy simulation of fire plumes, Proc. Proceedings of the Combustion Institute, 33(2), pp. 24732480, 2011.

[5] Chatterjee, P., de Ris, J.L., Wang, Y., and Dorofeev, S.B., A model for soot radiation in buoyant diffusion flames, Proceedings of the Combustion Institute, 33(2), pp. 2665-2671, 2011.

[6] Chatterjee, P., Krishnamoorthy, N., Wang, Y., de Ris, J.L., and Dorofeev, S.B., CFD simulation of radiative heat transfer between a buoyant turbulent fire and inert parallel panels, Proc. of the 12th Fire Science and Eng. Conf., INTERFLAM, Nottingham, UK, pp. 777-788, 2010.

[7] Krishnamoorthy, N., Chaos, M., Khan, M.M., Chatterjee, P., Wang, Y., and Dorofeev, S.B., Application of bench-scale material flammability data to model flame spread in medium -scale parallel panel test, Proc. of the 12th Fire Science and Eng. Conf., INTERFLAM, Nottingham, UK, pp. 709-720, 2010.

[8] Meredith, K.V., Xin, Y.B., and de Vries J., A numerical model for simulation of thin film water transport over solid fuel surfaces, Fire Safety Science, 10, pp. 415-428, 2011.

[9] Meredith, K.V., Heather, A., de Vries, and J., Xin Y., A numerical method for partially-wetted flow of thin liquid films, Computational Methods Multiphase Flow, VI, pp. 239-250, 2011.

[10] Khan, M.M., Jamison, K., and de Ris, J.L., Upward fire growth over thermally thin corrugated paperboard, Fire Safety Science 10, pp. 513-526, 2011.

[11] Chaos, M., Khan, M.M, Krishnamoorthy, N., Chatterjee, P., Wang, Y., and Dorofeev S.B, Experiments and modeling of single- and triple-wall corrugated material properties and fire behavior, Proc. of $12^{\text {th }}$ Fire and Mater. Conf., San Francisco, CA, 2011.

[12] Urbas, J. and Luebbers, G., The intermediate scale calorimeter development, Fire and Materials, 19, pp. 65-70, 1995. 
[13] ASTM E-1623, Standard test method for determination of fire and thermal parameters of materials, products and systems using an intermediate scale calorimeter (ICAL), American Society for Testing and Materials, West Conshohocken, PA, 2003.

[14] ISO/TR 14696, Reaction to fire tests, determination of fire parameters of materials, products, and assemblies using an intermediate scale calorimeter (ICAL), ISO, Geneva, 1999.

[15] Chaos, M., Khan, M.M., and Dorofeev, S.B., Pyrolysis of corrugated cardboard in inert and oxidative environments, Proceedings of the Combustion Institute, 34(2), pp. 2583-2590, 2013.

[16] Brehob, E.G., and Kulkarni, A.K., Experimental measurements of upward flame spread on a vertical wall with external radiation, Fire Safety Journal, 31, pp. 181-200, 1998.

[17] de Vries J., In-situ calibration of a microbolometer camera for the study of large-scale fires. Thermoscense: thermal infrared applications (SPIE) Baltimore, MD, 2013. (submitted). 